\title{
Cinemeducation in psychiatry
}

\section{Subodh Dave \& Kopal Tandon}

\begin{abstract}
SUMMARY
Psychiatry has had a significant influence on both Hollywood and world cinema. In turn, psychiatrists' fascination with psychiatric themes in films has inspired scores of books and bibliographies about films and psychiatry. Advances in medical education have led to the development of core-competencybased curricula for both undergraduate and postgraduate students. Learning objectives underpin such competencies. However, teaching competencies in the workplace is hampered by practical and ethical issues, especially in the case of psychiatric patients. Medical educationalists have found films to be a useful teaching tool with their larger-than-life vivid portrayals. In this article we demonstrate, with examples, the use of films and discrete film clips to achieve specific learning objectives that can be incorporated easily into most undergraduate and postgraduate teaching programmes in psychiatry.
\end{abstract}

\section{DECLARATION OF INTEREST}

None.

The relationship between films and psychiatry pre-dates the antipsychotic era and it is more than a century since the psychiatrist Dr Dippy first appeared on the silver screen. Rabkin (1998) and Gabbard (1999) have lamented the overwhelming negative portrayal of psychiatry and psychiatrists in commercial Hollywood cinema. Despite the Hollywood aphorism that 'there's no such thing as negative publicity', such negative portrayals have concerned psychiatrists because of their potential impact on public attitudes to mental illness (Fearing 1946). However, counterbalancing this concern was the awareness that the audio-visual medium had a role to play in medical education (Humphreys 1965; Smith 1974).

\section{Cinema, psychiatry and education}

Over the past 30 years, films such as those in Box 1 have been used to teach a range of psychiatric and generic medical topics such as cultural competency, child development, marital, family and group counselling, psychiatric diagnoses and clinical pharmacology (Alexander 2004a). Alexander coined the term 'cinemeducation' to explain his approach of using commercial film clips to teach psychosocial medicine (Alexander 1994). Psychiatry, with its close links to cinema, has been a fertile ground for medical educators interested in using cinema to teach not only psychosocial issues but also a range of diagnostic presentations (Hyler 1988; Robinson 2003; Wedding 2005) and their underlying psychopathology (Fritz 1979; Karlinsky 2003). Byrne (2009) outlined in this journal the reasons why psychiatrists should watch films. Here, we outline why and how psychiatrists should use films to teach psychiatry.

\section{Why films?}

Several factors have played a role in making films a popular tool for education. Films are an entertaining way of learning, well liked by students and, with advances in technology, now universally accessible on personal video and DVD players (Wedding 2005) as well as other portable digital devices. DVDs themselves are relatively cheap and web-based retailers such as Amazon or Lovefilm make it easy to buy or rent even rare, old-edition or international films.

Large-budget commercial films have an artistic richness that is often unmatched by tailor-made, small-budget documentaries. They also offer a vivid realistic portrayal of characters, generating empathy from the viewer. Unlike traditional teaching, which focuses on the language areas of the brain, films target both the auditory and visual areas (Bailey 1994). Educationalists have also grasped the fact that the larger-than-life portrayals

BOX 1 Useful films for teaching psychiatry

\begin{tabular}{ll}
\hline A Beautiful Mind (2001) & Schizophrenia \\
As Good as It Gets (1997) & Obsessive-compulsive disorder \\
Dennis the Menace (1993) & Attention-deficit hyperactivity disorder \\
Devrai (2004) & Schizophrenia \\
Girl, Interrupted (1999) & $\begin{array}{l}\text { Differential diagnosis: borderline personality } \\
\text { disorder or psychotic depression }\end{array}$ \\
Hannah and Her Sisters (1986) & Somatic complaints \\
Mr. Jones (1993) & Hypomania \\
Rainman (1988) & Autism \\
Some Voices (2000) & Schizophrenia \\
The Hours (2002) & Recurrent depressive illness \\
The Lost Weekend (1945) & Alcohol dependence \\
The Madness of King George (1994) & Organic mood disorder \\
What About Bob? (1991) & Countertransference
\end{tabular}

Subodh Dave is a consultant psychiatrist and Clinical Teaching Fellow at Derbyshire Mental Health NHS Trust, in Derby, UK. He has co-authored a psychiatry textbook for undergraduates and has an interest in experiential learning using films and simulated and volunteer patients. Kopal Tandon is a consultant in assertive outreach based at Millbrook Hospital in Mansfield, UK

Correspondence Dr Subodh Dave, Derbyshire Mental Health NHS Trust, Royal Derby Hospital, Uttoxeter Road, Derby DE22 3NE, UK.Email: subodh.dave@ derbysmhservices.nhs.uk 
in commercial cinema are more memorable and more likely to tap into students' emotional intelligence.

In psychiatry, films offer a resource to teach about sensitive clinical issues such as countertransference and risk assessment in a safe and ethically uncomplicated environment. This is particularly important in medical undergraduate education where students often report feeling intimidated by clinical encounters with patients. It is possible for students to express negative feelings about film characters when they may feel inhibited to do so about patients (Masters 2005). Fritz (1979) has argued that films, through their visual imagery, are closely related to dreams and therefore more likely to attune with the viewers' unconscious and primary process thinking.

Films offer students multiple perspectives on illness not usually seen in short psychiatry placements, for example those of a wider network of carers or of transcultural issues. Similarly, films can offer an opportunity to observe the long-term course of an illness (for example, Mr. Jones (1993) offers an insight into both depressive and manic phases of bipolar disorder) not usually afforded by short training posts. In an era of increasing medical student population, dwindling in-patient numbers and increasingly scattered community clinics, films offer a ready resource to teach large numbers of learners. On a practical note, films can be paused to deal with a discussion point or can be viewed repeatedly to emphasise particular learning objectives. Finally, films can be viewed by the student in the privacy of their own home or, as on our course, enjoyed as a group activity promoting team-based learning.

Commercial cinema does have its limitations. Teachers have to invest time in identifying appropriate films or film clips - but this is similar to designing any other teaching session. Learners must also invest time in watching films, although this is negligible for film clips and in any case will probably be far less than that needed to pursue similar information in the literature. The portrayals are often larger than life and because the films are not designed to deliver specific learning points they can convey and reinforce misconceptions (Greenberg 2009). For example, commercial films often show professionals socialising with patients and transgressing boundaries (Gharibeh 2005). However, even such negative images can be used to generate discussion and foster critical thinking.

\section{Educational context}

Over the past few decades, medical education has increasingly become competency-driven. Learning objectives form the building blocks of such

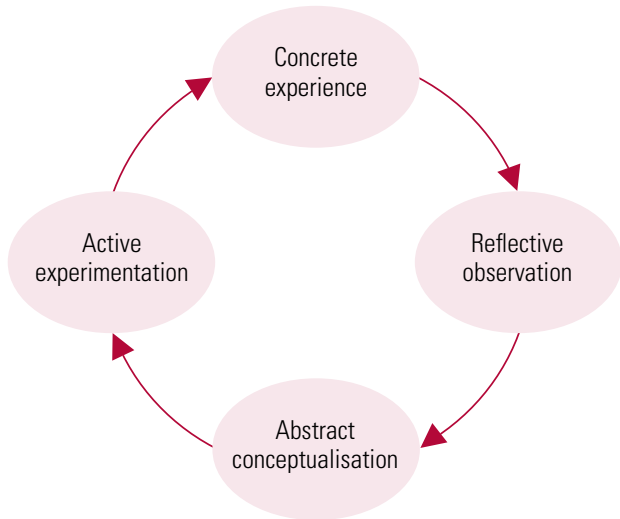

FIG 1 Kolb's learning cycle (Kolb 1984).

competencies. A learning objective is a statement describing a performance capability to be acquired by the learner. For example, to teach and measure achievement of the competency 'communicate empathically with carers', learning objectives such as 'explain to a carer the aetiology of schizophrenia using non-jargon terminology' can be used.

Medical school curricula are heavily biased in favour of biomedical science, to the detriment of medical humanities (Gordon 2003). Skills such as critical and reflective thinking, clinical ethical reasoning, values-based practice or narrative skills usually do not figure prominently in traditional medical curricula. Such skills are particularly relevant to psychiatric practice and have been clearly identified in Tomorrow's Doctors, the new undergraduate curriculum (General Medical Council 2009), and also in the new postgraduate competency-based curriculum (Royal College of Psychiatrists 2009).

According to Kolb (1984), 'learning is the process whereby knowledge is created through the transformation of experience'. Kolb's learning cycle (Fig. 1) emphasises the importance of experience followed by reflection, leading to alterations in thinking and behaviour that promote deep learning. This is exemplified in cinemeducation, which offers trainees a vicarious experience of mental illness, with an opportunity for reflective observation, and therefore a deeper understanding of the subject.

Based on our experience, we believe that using film clips with specific learning objectives allows for a targeted, more focused use of the clips and enables successful integration within existing teaching programmes.

\section{How to use films to teach}

\section{Materials needed}

Films can be easily bought online from reputable companies and the cost claimed from university teaching or library budgets. Most of the other 
equipment needed is usually already available at teaching institutions. Computers, attached to overhead projectors, are now frequently used by teachers to show presentations on whiteboards and the same equipment can be used to show films. The computer must have a DVD drive and DVD decoding software. Most computers with DVD drives have this software pre-installed or it may need to be bought. If buying new software, it is worth ensuring that it will allow you to bookmark film clips, so that they can be easily accessed during presentations. We have used Aimersoft Video Converter (available for both Macs and PCs), although there is other video-editing software such as AVS Video Editor and MPEG Video Wizard. Most sites offer 1-month free trial downloads, so it is worth trying the product before buying the licence. For international films or for DVDs with different formats (including Bluray or HD), we recommend the open-source VLC media player, which can open most video files, although it only has basic editing functions. It is beyond the scope of this article to teach the use of video-editing software but it is worth pointing out that newer software makes it as easy as loading the disc, identifying the start point of the film clip, fastforwarding to the end point and with a click the clip is created. This clip, stored as a file, can be imported into PowerPoint presentations or be posted as a hyperlink (see copyright caveat below).

\section{Copyright law}

The Copyright, Designs and Patent Act 1988 (under S34(2)) allows the showing of films or clips from films for non-commercial teaching purposes at teaching establishments before an audience comprising teachers and pupils, at whom the teaching is specifically aimed. This educational exemption is valid in some countries (such as the USA and the UK), but not in others (such as Canada). Some universities may have an institutional public performance licence and this may be worth checking with the local librarian.

Clips from films can also be copied for educational purposes according to S 32 of the Act. The Act separates copying done for examination purposes, for which there is no restriction on the method used to copy and display the clips, and that done for teaching purposes. For general teaching purposes, copying is not allowed by 'a reprographic process'. This includes electronic copying and therefore disallows copying clips for presentation software such as PowerPoint. Such copying falls into a grey area according to both the Motion Picture Licensing Corporation (www.mplcuk. com), which provides licences for the showing of films, and the Federation Against Copyright Theft (www.fact-uk.org.uk), which protects the UK's film industry against infringement of copyright. The Federation Against Copyright Theft suggests that permission should be sought from the film's production company. However, it could be argued that if film clips are used to carry out formative assessment for students, copyright is not infringed.

The 1988 Act does not restrict the length of clips copied from a film. However, there are restrictions placed on the copying of film scripts: the Act states that no more than $1 \%$ of published dramatic works can be copied in any one quarter by a teaching establishment.

\section{Using films to deliver learning objectives}

Films can be used either to engage students' attention by spicing up didactic presentations or to specifically fill gaps in the curriculum in the various domains of knowledge, skills and attitudes. Films have been used to impart knowledge, particularly of diagnostic criteria, for example those of attention-deficit hyperactivity disorder (ADHD) in Dennis the Menace (1993) (Shapiro 2007). Higgins (2001) has used films to teach diagnostic and treatment formulation skills. Films, however, come into their own as a teaching tool where the intention is to discuss sensitive issues such as countertransference (Swift 1993), particularly when dealing with demanding or difficult patients (Alexander 2004b), or to foster appropriate attitudes and combat subtle prejudices (Raingruber 2003).

Films can be screened in their entirety or selective clips can be used for particular learning objectives. Guided discussion is probably the commonest method of using films in teaching, but we have also found film clips to be useful in triggering role-plays because they provide a set of ready-made characters and circumstances for students to incorporate into their role-play. Box 2 gives an indication of the various ways that film clips can be used to meet learning objectives. This is not an exhaustive list because an average teaching programme may have scores of learning objectives, the delivery of most of which can be facilitated through films.

\section{Engage students' attention and illustrate symptoms}

An example of this is the introductory lecture in psychiatry for students at the University of Nottingham, UK. The lecture provides an overview of the ICD-10 classification with the diagnostic criteria of the major psychiatric disorders (World Health Organization 1992). We now use film clips from a range of films, including As Good as It Gets (1997; obsessive-compulsive disorder), The Madness of King George (1994; organic mood 
B0X 2 Examples of how to use films

Films can be used to:

- engage students' attention, emphasise learning points

in lectures and illustrate symptoms of a disorder

- stimulate discussion and promote self-reflection

- facilitate role-play

- illustrate the course of a disorder

- illustrate transcultural issues

disorder), Some Voices (2000; schizophrenia), Mr. Jones (1993; hypomania), Rainman (1988; autism) and The Lost Weekend (1945; alcohol dependence), to name a few. The clips can be played twice, before and after discussing the diagnostic criteria, enabling students to associate the criteria with the audio-visual representation before them.

\section{Stimulate discussion and promote self-reflection}

Films act as effective triggers for discussions. However, it is important to be clear about the learning objectives of the discussion. These may include discussion on diagnosis or management, reflection on one's own or others' emotional reactions, or merely observation of the characters' verbal and non-verbal communication. Zazulak (2002) suggests asking the following questions after presenting a film clip: 'What did you see? What did you hear? What did you feel? What did you think? What impact might this have on your clinical practice?'.

Girl, Interrupted (1999), starring Angelina Jolie and Winona Ryder, is often cited as exemplifying borderline personality disorder in Susanna, the lead character played by Ryder. However, in reality, the more appropriate diagnosis seems to be psychotic depression. The entire film can be screened, with a detailed discussion about diagnosis, or a short clip can be played that depicts Ryder discussing her condition with her psychiatrist and flying into a rage (located at 1:10:00-1:19:00), followed by a discussion about the appropriateness of making a diagnosis of borderline personality disorder in young Susanna.

We have found it useful to use a clip (0:14:00 0:18:20) from Hannah and Her Sisters (1986), a Woody Allen film, where Allen presents to his physician with a variety of somatic complaints. The clip arouses general mirth but offers a valuable trigger for asking students to reflect on the feelings generated in them on being faced with such a patient in primary care. The discussion can then proceed to the management of unexplained somatic symptoms in primary care.
Rainman (1988), starring Dustin Hoffman and Tom Cruise, is an Oscar-winning film. Hoffman won the award for his sensitive portrayal of autistic savant Raymond Babbitt, based on the real-life story of Bill Sackter, a friend of Barry Morrow, the director of the film. The film can be used to stimulate discussion on a variety of topics, including diagnostic criteria of autism-spectrum disorders, impact on carers and the role of institutional care, but is also excellent to demonstrate the range of verbal and motor tics and mannerisms displayed by Babbitt (0:36:30-0:38:24). Alexander's (2004a) suggestion of playing a clip without the audio and then with sound to aid the understanding of non-verbal communication is particularly relevant here.

\section{Facilitate role-play}

At Derby Medical School, UK, the medical students' psychiatric teaching programme includes 1 day a week of seminars covering one or two of the major psychiatric disorders. Role-plays are routinely used to teach a variety of skills, including interviewing, diagnostic and therapeutic skills. Each of these role-plays can be triggered using an appropriate film clip instead of a vignette. The advantage of using a clip in this situation is that it obviates the need to write detailed roleplays for the other characters. What About Bob? (1991; at 0:07:00-0:14:20) may not be an accurate portrayal of psychopathology but it does facilitate a role-play exploring countertransference towards Bob (Bill Murray), who is an extremely anxious, 'irritating and dependent' individual. In The Hours (2002), Julianne Moore plays housewife Laura, who leaves her son with a childminder to drive to a hotel to take a planned overdose of tablets. The role-play focuses on experiencing the thoughts and feelings of the father who might learn about this overdose attempt.

\section{Illustrate course of a disorder}

Mr. Jones (1993) stars Richard Gere as a man with bipolar disorder. In the first clip (0:45:00-0:53:09), we see $\mathrm{Mr}$ Jones displaying symptoms of severe depression. He appears dishevelled, confused, has psychomotor retardation and is seen walking in front of traffic. His flat also appears neglected and when he sees his psychiatrist, he is tearful. Students' understanding of mood disorders can be explored through probe questions such as: 'How would you describe Mr Jones's mental state? What diagnoses would you want to consider? What are the risks associated with Mr Jones's presentation?'

In the next two clips (0:02:30-0:09:52 and 0:15:40-0:23:23) Mr Jones has evidence of elevated 
mood in both his speech and his behaviour and the clips show some of the risks associated with disinhibited behaviour. In the first clip, he places his life at risk when he says he's going to fly to the ground from a roof. In the second clip, he goes on a spending spree with a woman he has just met and with whom he spends a night in a hotel. Again, the nature of the disorder can be elucidated through probe questions such as: 'What symptoms of elevated mood does Mr Jones display? How would you diagnose this particular episode of mood disturbance? What risks associated with mania do you see in these clips?'

By drawing the two discrete episodes together, the discussion can move on to the course of bipolar disorder and the key learning point (on our course), which is to 'ask about history of manic symptoms in a person presenting with depressive symptoms' to differentiate unipolar from bipolar depression.

\section{Illustrate transcultural issues}

Core competencies in both the undergraduate and postgraduate curricula include the ability to take a sociocultural history and knowledge of sociocultural considerations in patient presentations. These are notoriously difficult competencies to teach. Searles (2005) has taught cultural competencies to psychiatric trainees using movies (Boyz N the Hood (1991)and Platoon (1986)) to challenge ethnic stereotyping by showing the multiple perspectives that exist in particular situations (the Los Angeles ghetto and the Vietnam War respectively). Bhugra (2006) provides a transcultural Bollywood perspective on psychiatry in the Indian context.

In our own teaching, we have used the film Devrai (2004) to address a range of sociocultural issues. This non-Bollywood Marathi film, whose title means 'Sacred grove', was co-produced with the Schizophrenia Awareness Association in India. It is the story of Shesh, a young scientist (Atul Kulkarni) whose concern about environmental degradation in the countryside reaches excessive proportions, culminating in a psychotic episode. The focus of the film, however, is not on Shesh's heroic struggle with his illness, as in A Beautiful Mind (2001) (Box 3), but more on his younger sister Seena's (Sonali Kulkarni) struggle to cope with her brother's mental condition and maintain decorum in her family life. She finds herself caught between her need to look after her brother and to maintain peace with her husband, who has a largely unsympathetic understanding of Shesh's paranoid behaviour. Different characters in the film (Shesh's mother, other villagers, Shesh's brother-in-law) have different perspectives about the aetiology of

\section{B0X 3 A Beautiful Mind}

In A Beautiful Mind, Russell Crowe plays Nobel laureate John Nash, who was diagnosed with schizophrenia. Although the precise phenomenology of Nash's experiences is not evident from the clips, they can be used to prompt discussion of the positive symptoms typically experienced in schizophrenia. Clip 1 (0:31:000:37:00) shows 'Big Brother' informing Nash that he has been chosen to break a code used by Nazis, who plan to detonate a nuclear bomb in America. A microchip is embedded in Nash's forearm during this meeting. In clip 2 (0:55:00-1:03:00) we see Nash beginning to neglect his self-care and his work as he becomes increasingly unwell and paranoid. Clip 3 (1:22:00-1:35:00) shows him sitting, aimlessly wondering what other people do with their time. He also talks of side-effects, which lead him to stop his medication, resulting in a relapse. He accidentally hits his wife, partly in response to the hallucinations he is experiencing.

Shesh's condition. The film is worth watching in its entirety but useful discussions can be generated by the following clips: 0:06:14-12:50; 0:14:30-0:16:04; 0:23:00-0:25:40. The clips show Shesh responding to his hallucinations and attacking guests at a party thrown by his brother-in-law, thus embarrassing his host. The ensuing discussion between Seena and her husband shows how he indirectly blames her for 'shielding' him. The final clip shows Shesh's brother-in-law suggesting a referral to a psychiatrist while his mother suggests involving a witch doctor. Discussion questions include:

- What may be the psychosocial impact of mental illness on carers?

- What is the difference in the reaction of the sister and brother-in-law?

- How would you deal with carer stress in practice?

- This film is set in India - how would it be different if it was set in England?

- What 'transcultural' issues are evident in this clip?

- What is the difference between the mother's attitude to mental illness and that of Shesh's brother-in-law?

- How would you deal with such differences?

The discussion facilitates the key learning objectives of understanding the importance of universal values of human understanding and empathy and the risks of cultural stereotyping.

\section{Screening the whole film}

So far, we have discussed the delivery of specific learning objectives using selected film clips. For certain films, it may be best to screen it all. This 
may be particularly true for films with artistic merit and also allows for the attainment of multiple learning objectives. The Hours (2002) is one such film. It is a highly acclaimed Academy Award-winning film in which the lives of three women (Virginia Woolf, Laura and Clarissa) of different generations intertwine through Virginia Woolf's 1925 novel Mrs Dalloway. Woolf appears to have a severe recurrent depressive illness, with psychotic symptoms and previous suicide attempts. Laura, who is reading Mrs Dalloway, is a depressed housewife with a young son, stuck in an unhappy marriage. The film suggests that Laura was a shy and avoidant woman before her marriage. Clarissa, the embodiment of Mrs Dalloway, is struggling to come to terms with her friend Richard's diagnosis of AIDS. Richard was the love of her life and she projects onto him her own need to be loved and cared for. Richard is also Laura's son, and appears to be experiencing psychiatric sequelae of AIDS. It is a thought-provoking film that provides extensive material, particularly in the teaching of learning objectives pertinent to depression.

Whole-film screenings can be done as a part of face-to-face teaching, or the students can watch the film in their own private time followed by a discussion at the teaching seminar. Box 4 gives a list of learning objectives that can be met by screening the whole film.

\section{Integrating films into the existing curriculum}

Psychiatrists who are film buffs will have identified films that they want to use in teaching. However, most educators are busy clinicians and therefore may not have time to watch vast numbers of films.

BOX 4 Learning objectives for a full screening of The Hours (2002)

- To be able to list the symptoms (including psychotic) of depression

- To explain to a role-playing carer the epidemiology, aetiology and prognostic factors for depression

- To understand the recurrent nature of depression in some patients

- To be able to list the risk factors for depression, including the risk factors for suicide

- To record and discuss with a peer reflections on emotions generated within one's self following Laura's suicide attempt, with a discussion of factors hampering empathy towards people with mood disorders

- To be able to list the psychiatric sequelae of AIDS

- To be able to explain in role-play the impact of maternal depression on children and on other carers
B0X 5 Resources for identifying films to use in teaching psychiatry

- Cinemeducation (Alexander 2004a) lists discrete film clips with probe questions related to most psychiatric disorders and for more generic communication and treatment issues

- Movies and Mental IIIness. Using Films to Understand Psychopathology (Wedding 2005): a detailed bibliography of films illustrating psychopathology

- Reel Psychiatry. Movie Portrayals of Psychiatric Conditions (Robinson 2003): film portrayals of practically all conditions, usefully cross-referenced with DSM-IV or ICD-10 diagnostic criteria (American Psychiatric Association 1994; World Health Organization 1992)

- IMDb Top 250 (Internet Movie Database 2010): largest movie database with rankings based on viewer ratings

- A Summary of Films (Levine 2009): filmography from the Association of Directors of Medical Student Education in Psychiatry, USA, listing titles of more than 100 feature films depicting various psychiatric disorders

- Special Issue on Cinema; International Review of Psychiatry (Bhugra 2009): a useful collection of articles relating to films and psychiatry

There are hundreds of films available as teaching materials. There are many resources (listed in Box 5) that can help to identify an appropriate film for teaching. It is important to recognise that films are but one of many resources available for teaching, and therefore the most effective strategy is to review the existing teaching programme to identify current learning objectives that can be better achieved through the use of films, or devise new ones that are needed to deliver curricular goals. Consideration should then be given to whether specific films from the examples listed or from bibliographies mentioned can meet these learning objectives. Readers will note that this is an exercise in curricular mapping, a staple of all course organisers. Films thus form an additional tool to help facilitate learning rather than replacing any other learning activity. Special study modules on 'Films and psychiatry' are now available in many universities and are aimed at fostering medical students' interest in psychiatry (Akram 2009). Detailed description of such modules is beyond the scope of this article but we run such a module and readers are encouraged to contact us for further information.

Box 6 lists some tips on integrating films into the curriculum and Box 7 provides an example of how we have incorporated films into the teaching of schizophrenia to medical students. 
BOX 6 Tips on integrating films into the existing curriculum

- First, identify your learning objectives, then think about the purpose of the clip/film and how this aids you in delivering those

- Make the educational context of the clip or film explicit

- Use films/clips selectively - do not drown the curriculum in films

- Prepare lead-in comments/questions for active watching, for example: 'While watching this clip think about why the relative is responding in this way' or 'What might you do to change the relative's perception?'

- Prepare follow-up questions and resources (for example, read the Royal College of Psychiatrists' Depression leaflet (2010) after watching The Hours (2002))

- Use Kolb's learning cycle (Fig. 1) - allow students time for reflective observation, abstract conceptualisation and, where possible, active experimentation after the clip, even if this is only a 2-minute discussion with the person sitting next to them

\section{Conclusions}

Films provide an entertaining and informative tool in the modern clinical educators' armamentarium. They integrate effortlessly with existing formats of teaching such as lectures, role-play or small-group discussions, and can be used to teach a range of competencies identified in undergraduate and postgraduate psychiatric curricula. The advent of digital media and web-based retailers has made films accessible to all. Hollywood has an eternal fixation with psychiatry, but international films increasingly feature psychiatric themes, offering teachers in psychiatry a potentially infinite teaching resource.

\section{Acknowledgement}

We would like to thank Dr Mary Wheatcroft for her involvement in cinemeducation in Derby.

\section{References}

Akram A, Obrien A, O'Neill A (2009) Crossing the line. Learning psychiatry at the movies. International Review of Psychiatry 21: 267-8.

Alexander M, Hall M, Pettice Y (1994) Cinemeducation. An innovative approach to teaching psychosocial medical care. Family Medicine 26: $430-3$.

Alexander M (2004a) A review of the literature. In Cinemeducation (eds M Alexander, P Lenehan, A Pavlov): 3-7. Radcliffe Publishing.

Alexander M, Williams J (2004b) The difficult patient. In Cinemeducation (eds M Alexander, P Lenehan, A Pavlov): 137-40. Radcliffe Publishing.

American Psychiatric Association (1994) Diagnostic and Statistical Manual of Mental Disorders (4th edn) (DSM-IV). APA.
BOX 7 Learning objectives of the schizophrenia teaching day for medical students

\section{Films used}

A Beautiful Mind (Box 3) and Devrai

(described on p. 305)

\section{Learning objectives} schizophrenia and define a hallucination and delusion (lecture slides enlivened through use of clips 1 and 2 from $A$ Beautiful Mind)

- Be able to list the negative symptoms of schizophrenia and the differential diagnoses for negative symptoms (illustrated lecture and discussion stimulated by screening clip 3)

- Diagnosis and classification: identify the different subtypes of the disorder. Be able to make a differential diagnosis in a patient with schizophrenia (discussion stimulated through use of clips 1 and 2)

- Be able to carry out a risk assessment in a simulated patient with schizophrenia (use clip 3 to trigger role-play)

- Discuss in peer group the principles of the treatment for schizophrenia using a biopsychosocial model (discussion stimulated by clips from Devrai: 0:48:47-0:49:47 and 1:22:45-1:23:45)
- Be able to list the first-rank symptoms of
- Use National Institute for Health and Clinical Excellence (NICE) guidelines for the treatment of schizophrenia for Mr Nash (clips 1, 2 and 3)

- Be able to interview a patient with psychosis (can use a clip from $A$ Beautiful Mind to trigger role-play)

- Communicate effectively with both patients and carers to explain diagnosis, foster adherence to treatment and discuss Devrai can be used to trigger role-play)

- Be able to assess risk and develop an appropriate management plan for a patient with schizophrenia (can be facilitated by screening clip 3 from $A$ Beautiful Mind

- Be able to make a biopsychosocial management plan for patients with schizophrenia

- Be respectful towards patients (clinical placement-based teaching)

- Empathy for those with schizophrenia (discussion after watching clips from Devrai) schizophrenia and elicit symptoms of prognosis of schizophrenia (clips from

Bailey D, Ledford B (1994) The feature film as an instructional medium. International Journal of Instructional Media 21: 147-54.

Bhugra D (2006) Mad Tales from Bollywood. Psychology Press.

Bhugra D, Gupta S (2009) Editorial. International Review of Psychiatry 21: $181-2$.

Byrne $\mathrm{P}$ (2009) Why psychiatrists should watch films (or What has cinema ever done for psychiatry?). Advances in Psychiatric Treatment 15: 286-96.

Fearing F (1946) Psychology and the films. Hollywood Quarterly 2: 118-21.

Fritz G, Poe R (1979) The role of a cinema seminar in psychiatric education. American Journal of Psychiatry 36: 207-10.

Gabbard K, Gabbard G (1999) Psychiatry and the Cinema (2nd edn). American Psychiatric Press

General Medical Council (2009) Tomorrow's Doctors. GMC.

Gharibeh N (2005) The psychiatrist's image in commercially available American movies. Acta Psychiatrica Scandinavica 111: 316-319.

Greenberg H (2009) Caveat actor, caveat emptor. Some notes on some hazards of Tinseltown teaching. International Review of Psychiatry 21: $241-4$.

Gordon J, Evans M (2003) Understanding Medical Education. Learning from the Humanities. Association for the Study of Medical Education.

Higgins J, Dermer S (2001) The use of cinema in marriage and family counsellor education. Counselor Education and Supervision 40: 183-93.

Humphreys M, Nesmith L, Pohl S, et al (1965) Development of a reviewing procedure for audiovisual materials by students of medicine. Journal of Medical Education 40: 742-52.
MCO answers

$1 d \quad 2$ a $\quad 3$ a $\quad 4 d \quad 5$ a 
Hyler S (1988) DSM-III at the cinema. Madness in the movies. Comprehensive Psychiatry 29: 195-206.

Internet Movie Database (2010) IMDb Top 250. IMDb (http://www.imdb. com/chart/top)

Karlinsky H (2003) Doc Hollywood north. Part I. The educational applications of movies in psychiatry. CPA Bulletin 35: 9-12.

Kolb D (1984) Experiential Learning. Prentice Hall.

Levine R (2009) A Summary of Films. Association of Directors of Medical Student Education in Psychiatry (http://www.admsep.org/cinema.html).

Masters $\mathrm{J}$ (2005) Hollywood in the classroom. Using feature films to teach. Nurse Educator 30: 113-6.

Rabkin L (1998) The Celluloid Couch An Annotated International Filmography of the Mental Health Professional in the Movies and Television, from the Beginning to 1990. Scarecrow Press.

Raingruber B (2003) Integrating aesthetics into advanced practice mental health nursing. Commercial film as a suggested modality. Issues in Mental Health Nursing; 24: 467-95.

Robinson D (2003) Reel Psychiatry. Movie Portrayals of Psychiatric Conditions. Rapid Psychler Press.
Royal College of Psychiatrists (2009) A Competency-Based Curriculum for Specialist Training in Psychiatry. RCPsych (http://www.rcpsych.ac.uk/ training/curriculum2010/curriculum2009.aspx).

Royal College of Psychiatrists (2010) Depression. RCPsych (http:// www.rcpsych.ac.uk/mentalhealthinformation/mentalhealthproblems/ depression/depression.aspx).

Searles $F(2005)$ Using film as the basis of an American culture course for first-year psychiatry residents. Academic Psychiatry 29: 100-4.

Shapiro $\mathrm{J}$ (2007) Literature and arts in medical education. Family Medicine 39: 20-3.

Smith J (1974) The movie as medium for the message. Perspectives in Psychiatric Care 12: 157-64.

Swift WJ, Wonderlich S (1993) House of Games: a cinematic study of countertransference. American Journal of Psychotherapy 47: 38-57.

Wedding D, Boyd M, Niemiec R (2005) Movies and Mental IIIness. Using Films to Understand Psychopathology. Hogrefe and Huber.

World Health Organization (1992) The ICD-10 Classification of Diseases, Clinical Descriptions and Diagnostic Guidelines. WHO.

Zazulak J (2002) Let Hollywood help you teach. SOT Newsletter 10: 6 .

\section{MCOs}

Select the single best option for each question stem

1 Under the Copyright, Designs and Patent Act 1988:

a it is necessary to have a licence to show clips from films for non-commercial teaching purposes

b a licence is always required to screen a whole film for non-commercial teaching purposes

c there is a limit to the length of clips that can be copied from a film for teaching purposes without a licence

$d$ there are no restrictions to the methods used to copy and display film clips for examination purposes

e copying segments of films for display through presentation software, such as PowerPoint, for non-commercial teaching purposes is allowed.

2 Considering the practicalities of film clips:

a most computer DVD decoding programs allow for film clips to be bookmarked so it is unnecessary to forward and rewind to the correct position

b specialist equipment will need to be purchased before film clips can be incorporated into teaching programmes c DVDs cannot be bought as part of a university or trust library budget

$\mathrm{d}$ it is important for trainers to undergo a training course in film editing before using films to teach

e only British films can be used for teaching purposes.

3 Learning objectives:

a ensure that competencies outlined in curricula are achieved

b cannot be achieved through the use of film clips

c involving fostering positive attitudes towards patients with mental illness cannot be achieved through the use of Hollywood films

$d$ involving discussion of sensitive issues such as countertransference are not aided by the use of film clips

e produced through role-play should not involve film clips as triggers.

4 Educators interested in using film as a resource will find that:

a it is difficult to find information on films that may be suitable for teaching

b there has been little interest by medical educators in the use of films for teaching psychiatry c film clips cannot readily be incorporated into an existing teaching program

$\mathrm{d}$ there are books available that provide the timings of clips, together with suggested probe questions

e Hollywood films can be used to teach DSM-IV but not ICD-10 diagnostic criteria.

5 When selecting films to teach psychiatry:

a Devraican be used to illustrate transcultural differences in carers' views towards mental illness

b Mr. Jones cannot be used to illustrate differential diagnosis between unipolar and bipolar depression

c Devrai provides little scope to help students appreciate the psychosocial impact of menta illness on carers

$\mathrm{d}$ the learning objectives for The Hours mainly focus on the acquisition of knowledge about the symptoms of psychotic depression

e Hannah and Her Sisters explores the psychological sequelae of the diagnosis of a serious medical illness. 